\title{
G protein-linked signaling pathways in bipolar and major depressive disorders
}

\author{
Hiroaki Tomita ${ }^{1,2,3}$, Mary E. Ziegler ${ }^{1,3}$, Helen B. Kim ${ }^{1,3}$, Simon J. Evans ${ }^{4}$, Prabhakara V. Choudary ${ }^{5}$, \\ Jun Z. Li ${ }^{4}$, Fan Meng ${ }^{4}$, Manhong Dai ${ }^{4}$, Richard M. Myers ${ }^{6}$, Charles R. Neal ${ }^{4,7}$, Terry P. Speed ${ }^{8}$, \\ Jack D. Barchas ${ }^{9}$, Alan F. Schatzberg ${ }^{10}$, Stanley J. Watson ${ }^{4}$, Huda Akil ${ }^{4}$, Edward G. Jones ${ }^{5}$, \\ William E. Bunney ${ }^{1}$ and Marquis $P$. Vawter ${ }^{1,3 *}$
}

\author{
${ }^{\prime}$ Department of Psychiatry and Human Behavior, University of California, Irvine, CA, USA \\ ${ }^{2}$ Department of Biological Psychiatry, Tohoku University, Sendai, Japan \\ ${ }^{3}$ Functional Genomics Laboratory, Department of Psychiatry and Human Behavior, University of California Irvine, CA, USA \\ ${ }^{4}$ Molecular and Behavioral Neurosciences Institute, University of Michigan, Ann Arbor, MI, USA \\ ${ }^{5}$ Center for Neuroscience, University of California, Davis, CA, USA \\ ${ }^{6}$ HudsonAlpha Institute for Biotechnology, Huntsville, AL, USA \\ 7 John A. Burns School of Medicine, University of Hawaii, Honolulu, HI, USA \\ ${ }^{8}$ Department of Statistics, University of California Berkeley, CA, USA \\ ${ }^{9}$ Department of Psychiatry, Weill Cornell Medical College, New York, NY, USA \\ ${ }^{10}$ Department of Psychiatry and Behavioral Sciences, Stanford University, Palo Alto, CA, USA
}

\section{Edited by:}

Kathleen D. Askland, Brown

University, USA

\section{Reviewed by:}

Pamela B. Mahon, Johns Hopkins School of Medicine, USA

Michael P. McDonald, University of Tennessee Health Science Center, USA

\section{*Correspondence:}

Marquis P. Vawter, Functional

Genomics Laboratory, Department

of Psychiatry and Human Behavior,

University of California, Irvine,

CA 92697-4260, USA

e-mail:mvawter@uci.edu
The G-protein linked signaling system (GPLS) comprises a large number of G-proteins, G protein-coupled receptors (GPCRs), GPCR ligands, and downstream effector molecules. G-proteins interact with both GPCRs and downstream effectors such as cyclic adenosine monophosphate (CAMP), phosphatidylinositols, and ion channels. The GPLS is implicated in the pathophysiology and pharmacology of both major depressive disorder (MDD) and bipolar disorder (BPD). This study evaluated whether GPLS is altered at the transcript level. The gene expression in the dorsolateral prefrontal (DLPFC) and anterior cingulate (ACC) were compared from MDD, BPD, and control subjects using Affymetrix Gene Chips and real time quantitative PCR. High quality brain tissue was used in the study to control for confounding effects of agonal events, tissue $\mathrm{pH}$, RNA integrity, gender, and age. GPLS signaling transcripts were altered especially in the ACC of BPD and MDD subjects. Transcript levels of molecules which repress CAMP activity were increased in BPD and decreased in MDD. Two orphan GPCRs, GPRC5B and GPR37, showed significantly decreased expression levels in MDD, and significantly increased expression levels in BPD. Our results suggest opposite changes in BPD and MDD in the GPLS, "activated" CAMP signaling activity in BPD and "blunted" CAMP signaling activity in MDD. GPRC5B and GPR37 both appear to have behavioral effects, and are also candidate genes for neurodegenerative disorders. In the context of the opposite changes observed in BPD and MDD, these GPCRs warrant further study of their brain effects.

Keywords: G-protein coupled receptor (GPCR), transcriptome, bipolar disorder, major depressive disorder, GPR37, GPRC5B, cyclic AMP, phosphatidylinositol

\section{INTRODUCTION}

The G-protein linked signaling system (GPLS) comprises Gproteins, G protein-coupled receptors (GPCRs), GPCR ligands, and downstream effector molecules. G-proteins interact with both GPCRs and downstream effectors such as cyclic adenosine monophosphate (cAMP), phosphatidylinositols, and ion channels. The GPLS is implicated in the pathophysiology and pharmacology of both major depressive disorder (MDD) and bipolar disorder (BPD). GPCRs are integral membrane proteins with key roles in numerous physiological cellular processes. GPCRs can signal ligand binding events by conformational changes that activate intracellular $G$ proteins. Active $G$ proteins in turn trigger intracellular downstream signaling pathways. Evidence suggests that altered GPCRs and their two major downstream signaling pathways, mediated by effectors such as cAMP and phosphatidylinositol, may be involved in the pathophysiology of BPD and MDD as well as in the mechanism of drug treatment for these disorders. Altered immunoreactivities and functional activities of proteins related to CAMP signaling pathways have been reported in the brain and peripheral blood cells of BPD patients (Jope et al., 1996; Karege et al., 1996; Gould and Manji, 2002; Chang et al., 2003). Also, mood stabilizers and antidepressants have been shown to affect cAMP and phosphatidylinositol signaling (Donati and Rasenick, 2003; Harwood, 2005; Xu et al., 2007; Racagni and Popoli, 2008). There are at least 210 GPCRs for which a natural ligand has been identified. There are 150 orphan GPCRs, with no known ligand or function (Wise et al., 2004), that might be relevant to downstream signaling dysregulation observed in 
BPD and MDD. Among the signal transmission systems associated with GPCRs, monoaminergic, and neuropeptidergic systems are believed to be dysregulated in BPD and MDD (Lieb et al., 2002; Elhwuegi, 2004; Carvajal et al., 2006; Ruhe et al., 2007).

Messenger RNA expression levels of a number of GPCRs, their ligands, and effector molecules involved in the GPLS pathways have been measured in post-mortem brains of BPD and MDD patients (Young et al., 1996; Spleiss et al., 1998; Caberlotto and Hurd, 2001; Kuromitsu et al., 2001; Zhou et al., 2001; Gurevich et al., 2002; Pandey et al., 2002; Agam et al., 2003; Chang et al., 2003; Dwivedi et al., 2004; Escriba et al., 2004; Lopez-Figueroa et al., 2004; Sherrin et al., 2004). Brain imaging studies have implicated anterior cingulate cortex (ACC) and the dorsolateral prefrontal cortex (DLPFC) in the pathophysiology of mood disorders (Harrison, 2002; Rogers et al., 2004; Frazier et al., 2005). In this study, the DLPFC and ACC were selected for microarray gene expression profiling of BPD and MDD patients focusing on the involvement of genes involved in GPLS pathways in these disorders and the effect of drug treatments. These cortical regions were selected because of the integral role of the ACC and DLPFC in the control of impulses, memory, learning, and hedonic evaluation, and depression. This study compares an a priori set of genes, in both mood disorders, using two cortical regions. There have been a number of previous studies comparing MDD and BPD by microarray analysis to controls, e.g., studies involving samples from the Stanley Foundation Neuropathology Brain collection (Kim and Webster, 2010). However, few studies have analyzed gene expression by microarray analysis of the Anterior Cingulate in both mood disorder groups, aside from studies involving the Pritzker Neuropsychiatric Disorders papers which involved selected pathways of glutamate, mitochondria, and growth factors (Evans et al., 2004; Choudary et al., 2005; Vawter et al., 2006). We hypothesized that there would be dysregulation of the GPLS in both mood disorders compared to controls, and that some overlap between the signature of each mood disorder would be found, given that most of our subjects were in a depressive state near the time of death.

\section{MATERIALS AND METHODS SUBJECTS}

The primary cohort consisted of 22 subjects, including seven healthy controls, six patients with bipolar disorder type I (BPD), and nine patients with MDD (Cohort A). The MDD results were validated with an additional independent cohort, including seven controls and five MDD patients (Cohort B). Toxicology data and/or recent clinical data were examined for the BPD and MDD subjects and detailed clinical information is summarized in Table 1. To minimize potential confounding effects of agonal events, we used three criteria in subject selection: brain tissue $\mathrm{pH}$ of $>6.6$, ribosomal RNA $28 \mathrm{~S} / 18 \mathrm{~S}$ ratio of $>1.5$, and sudden death with the agonal period lasting less than $1 \mathrm{~h}$. We have previously found large differences in gene expression values when using longer agonal periods, $>1 \mathrm{~h}$ and as long as 1-2 days, and would have found large effects due only to mixing samples with long and short agonal duration (Li et al., 2004; Tomita et al., 2004; Vawter et al., 2006; Atz et al., 2007).
Brain tissue and clinical information were obtained by the UCI Brain Bank staff with the informed consent of decedents' next-ofkin, and were processed through a standard protocol approved by the local UCI Institutional Review Board (Tomita et al., 2004). None of the subjects included in this study had specific agonal conditions including cancer, hypoxia, coma, pyrexia, seizure, dehydration, hypoglycemia, multi-organ failure, skull fracture, ingestion of neurotoxic substances or prolonged agonal duration, which are known to affect tissue $\mathrm{pH}$, RNA integrity and gene expression profiles in post-mortem brain (Li et al., 2004; Tomita et al., 2004). The variables for gender, age, post-mortem interval (PMI), tissue $\mathrm{pH}$, and 28S/18S ratio were balanced between diagnostic and control groups. Patients who were prescribed lithium and selective serotonin reuptake inhibitor (SSRI) at the time of death are also indicated (Table 1).

\section{MICROARRAY GENE EXPRESSION}

The experimental procedures are described elsewhere (Evans et al., 2004; Tomita et al., 2004). Total RNA was extracted from ACC and DLPFC of Cohort A (Table 1), and purified with silicabased mini-spin columns (Qiagen, Valencia, California). The oligonucleotide microarray experiments were conducted utilizing Affymetrix U133A Gene Chips following the manufacturer's protocol (Affymetrix, Santa Clara, CA). To detect gene expression differences between diagnostic groups reliably, we replicated the experiments as follows: Cohort A used 22 subjects' total RNA from ACC which were processed at two laboratories (University of California, Irvine and University of California, Davis) and DLPFC that were processed independently (University of California, Davis and University of Michigan, Ann Arbor). For Cohort B 12 total RNA samples from ACC and DLPFC (additional 12 subjects) were processed at the same independent laboratories as cohort A. In summary, for each BPD subject there were duplicate arrays run, and for MDD subjects there were duplicate arrays run, plus an additional cohort of MDD subjects were run also with duplicate arrays.

\section{DATA ANALYSES}

Since a considerable number of probe sequences in the Affymetrix original chip definition file (CDF) were found to incorrectly BLAST to other transcripts, a refined CDF based on an UniGene cluster was developed (Evans et al., 2004; Dai et al., 2005), and was used for data analyses presented in this paper. The refined CDF file is available on http://brainarray.mhri.med.umich.edu/brainarray/.

The focus of this study was 445 GPLS genes found on the Affymetrix arrays used in this study (Table S1). Signal intensities were extracted with Robust Multi-array Average (RMA) for each probe set and each subject. Gene-wise Pearson's correlation coefficients between experimental duplicates were calculated. Only the genes that were significantly correlated $(p<0.05)$ between experimental duplicates were considered to be reliably measured genes, and were subjected to downstream analyses. These genes were analyzed in a mixed-model ANOVA utilizing Partek Pro 6.0 (Partek, MO) for the main effect of the diagnostic classification (BPD, MDD, control) and for sex (Evans et al., 2004). We calculated the false discovery rate (FDR) in the microarray 
Table 1 | Demographics of two cohorts with mood disorder and matched controls, Cohorts A and B.

\begin{tabular}{|c|c|c|c|c|c|c|c|c|}
\hline Gender (L) ${ }^{a}$ & Age & Diagnosis & PMI & pH & $28 S / 18 S$ & SSRI $\mathbf{l}^{\mathbf{b}}$ & Manner of death & Medications, time of death \\
\hline \multicolumn{9}{|c|}{ COHORT A (BPD, MDD, CONTROL) } \\
\hline Male & 9 & BPD & 11.25 & 6.91 & 1.55 & NP & Exsanguination rupture of aorta & \\
\hline Male (L) & 3 & BPD & 9 & 7.12 & 2.1 & NP & Hanging & $\begin{array}{l}\text { Mood Stabilizer, Antipsychotic, } \\
\text { Anticholinergic }\end{array}$ \\
\hline Male (L) & 26 & BPD & 19 & 6.92 & 1.81 & NP & Carbon monoxide poisoning & $\begin{array}{l}\text { Antipsychotic, Mood Stabilizer, } \\
\text { Mood Stabilizer, Antianxiety } \\
\text { Agent, Anticholinergic }\end{array}$ \\
\hline Female & 56 & BPD & 29 & 6.83 & 2.17 & SSRI+ & Acute strychnine intoxication & $\begin{array}{l}\text { Antidepressant-Atyp }{ }^{\#}, \\
\text { Antidepressant-HCA } \\
\text { Antianxiety Agent, Hypnotic, } \\
\text { Antidepressant-SSRI }\end{array}$ \\
\hline Male & 52 & BPD & 28 & 7.05 & 2.36 & NP & $\begin{array}{l}\text { Acute hemorrhage slash wound to } \\
\text { neck }\end{array}$ & \\
\hline Male (L) & 59 & BPD & 15.5 & 6.99 & 1.58 & NP & Myocardial infarction & Mood Stabilizer \\
\hline Female & 72 & MDD & 21 & 7.13 & 2.28 & NP & $\begin{array}{l}\text { Pulmonary edema due to acute } \\
\text { intoxication }\end{array}$ & $\begin{array}{l}\text { Hypnotic, Antianxiety Agent, } \\
\text { Antianxiety Agent, } \\
\text { Antidepressant-HCA, } \\
\text { Antidepressant-HCA }\end{array}$ \\
\hline Male & 19 & MDD & 18 & 7.11 & 2.17 & NP & Asphyxiation due to hanging & \\
\hline Male & 58 & MDD & 24 & 6.93 & 2.26 & SSRI+ & Hanging & $\begin{array}{l}\text { Antidepressant-SSRI, } \\
\text { Antidepressant-Atyp }\end{array}$ \\
\hline Male & 49 & MDD & 31 & 7 & 1.96 & SSRI+ & $\begin{array}{l}\text { Accidental overdose of propoxyphene, } \\
\text { norpropoxyphene, amitriptyline, } \\
\text { nortriptyline, sertaline, norsertaline } \\
\text { and zolpidem }\end{array}$ & $\begin{array}{l}\text { Antidepressant-SSRI, Antianxiety } \\
\text { Agent, Hypnotic, } \\
\text { Antidepressant-HCA }\end{array}$ \\
\hline Male & 46 & MDD & 27 & 6.91 & 2.07 & NP & $\begin{array}{l}\text { Occlusion of left anterior descending } \\
\text { coronary artery }\end{array}$ & $\begin{array}{l}\text { Hypnotic, Antianxiety Agent, } \\
\text { Antianxiety Agent }\end{array}$ \\
\hline Male & 49 & MDD & 27 & 7.19 & 2.24 & NP & Hanging & \\
\hline Male & 52 & MDD & 16 & 6.82 & 1.82 & SSRI+ & Acute myocardial infarction & $\begin{array}{l}\text { Antidepressant-SSRI, } \\
\text { Antidepressant-Atyp, } \\
\text { Antipsychotic, Hypnotic }\end{array}$ \\
\hline Female & 48 & MDD & 37 & 6.95 & 1.86 & SSRI+ & Overdose morphine & $\begin{array}{l}\text { Anticonvulsant, } \\
\text { Antidepressant-SSRI, Antianxiety } \\
\text { Agent }\end{array}$ \\
\hline Male & 39 & MDD & 27.5 & 6.79 & 1.77 & SSRI+ & Hanging & $\begin{array}{l}\text { Anticonvulsant, } \\
\text { Antidepressant-SSRI }\end{array}$ \\
\hline Female & 60 & Control & 24 & 6.99 & 1.77 & NA & Myocardial infarction & \\
\hline Male & 70 & Control & 27 & 7.03 & 1.89 & NA & Myocardial infarction & \\
\hline Male & 18 & Control & 22 & 6.97 & 2.53 & NA & Freshwater drowning & \\
\hline Male & 58 & Control & 26 & 7.02 & 1.99 & NA & Ventricular fibrillation & \\
\hline Male & 55 & Control & 18 & 6.89 & 2.2 & NA & Myocardial infarction & \\
\hline Male & 45 & Control & 21 & 6.86 & 1.92 & NA & Congestive heart failure & \\
\hline Male & 44 & Control & 23 & 6.87 & 1.9 & NA & Myocardial infarction & \\
\hline \multicolumn{9}{|c|}{ COHORT B (MDD, CONTROL) } \\
\hline Male & 35 & MDD & 24.75 & 7.04 & 2.14 & NP & Hanging & Antidepressant-Atyp $\#$ \\
\hline Male & 47 & MDD & 29 & 7.25 & 2.08 & NP & Hanging & \\
\hline Female & 80 & MDD & 15 & 6.68 & 2.21 & NP & Hypertrophic cardiomyopathy & \\
\hline Male & 63 & MDD & 28.5 & 7.17 & 1.57 & NP & Ruptured aortic abdominal aneurysm & \\
\hline Male & 66 & MDD & 32 & 7.05 & 2.07 & SSRI+ & Cardiac event & Antidepressant-SSRI \\
\hline Male & 77 & Control & 7.25 & 6.62 & 2.16 & NA & Cardiac event & \\
\hline Male & 39 & Control & 18 & 6.81 & 1.67 & NA & Cardiac arrhythmia & \\
\hline Male & 39 & Control & 30 & 7.02 & 1.88 & NA & Electrocution & \\
\hline
\end{tabular}


Table 1 | Continued

\begin{tabular}{|c|c|c|c|c|c|c|c|c|}
\hline Gender (L) ${ }^{a}$ & Age & Diagnosis & PMI & pH & $28 S / 18 S$ & SSRI $^{\mathbf{b}}$ & Manner of death & Medications, time of death \\
\hline Male & 41 & Control & 22.5 & 7.01 & 2.08 & NA & Severe coronary arteriosclerosis & \\
\hline Male & 65 & Control & 13.5 & 6.88 & 2.05 & NA & Hemorrhagic pericarditis & \\
\hline Male & 49 & Control & 27.5 & 6.68 & 1.68 & NA & Coronary Insufficiency & \\
\hline Female & 45 & Control & 32 & 6.6 & 1.71 & NA & $\begin{array}{l}\text { Bilateral extensive pulmonary } \\
\text { embolism }\end{array}$ & \\
\hline
\end{tabular}

${ }^{a} L$, prescribed lithium at time of death.

\#Antidepressant-Atypical, Antidepressant-heterocyclic.

Mean + standard deviation of age: BPD, $47.5 \pm 18.7 ; M D D, 48.0 \pm 14.2 ;$ control, $50 \pm 16.7$.

Mean + standard deviation of PMI: BPD, 18.6 8.4; MDD, 25.4 \pm 6.5 ; control, 23.0 \pm 3.1.

Mean + standard deviation of $\mathrm{pH}: B P D, 7.0 \pm 0.1 ; \mathrm{MDD}, 7.0 \pm 0.1 ;$ control, $6.9 \pm 0.1$.

Mean + standard deviation of 28S/18S: BPD, $1.9 \pm 0.3 ; M D D, 2.0 \pm 0.2 ;$ control, $2.0 \pm 0.3$.

Mean \pm standard deviation of age: MDD, $58.2 \pm 17.5 ;$ control, $50.7 \pm 14.7$.

Mean \pm standard deviation of PMI: MDD, 25.9 \pm 6.6 ; control, $21.5 \pm 9.1$.

Mean \pm standard deviation of $\mathrm{pH}: \mathrm{MDD}, 7.0 \pm 0.2$; control, $6.8 \pm 0.2$.

Mean \pm standard deviation of 28S/18S: MDD, $2.0 \pm 0.3$; control, $1.9 \pm 0.2$.

${ }^{b} N$, not prescribed SSRI; NA, not applicable for SSRI.

study by Benjamini-Hochberg step-down procedure using Partek Genomics setting the FDR to 0.05 . Since the three diagnostic groups were well matched on age and $\mathrm{pH}$ (Table 1), the gene expression values were not tested by ANCOVA. However, in posthoc analysis, we determined whether the tissue $\mathrm{pH}$ was correlated with any differentially expressed GPLS genes. The post-hoc analysis showed that there were no significant correlations found with tissue $\mathrm{pH}$ and differentially expressed GPLS genes. A post-hoc group comparison of subjects with SSRI treatment and without treatment was conducted in MDD subjects, and similar analysis for lithium was conducted for BPD subjects.

The hypergeometric distribution was used for calculating probabilities that the observed number of genes in each gene category for cAMP or PI signaling pathways (listed in Table S2) were detected as differentially expressed genes in the comparisons between patients and control. False discovery rate were evaluated by QVALUE (Storey and Tibshirani, 2003). Calculations for hypergeometric probabilities were performed using SISA online statistics package (http://www.quantitativeskills.com/sisa/ distributions/hypergeo.htm).

\section{QUANTITATIVE PCR}

For further technical evaluation of the microarray data, we evaluated mRNA expression levels by quantitative real-time reverse transcriptase PCR (qPCR) for the seven genes listed in Table 3. We followed up on results primarily that met FDR in cohort A for BPD, and both Cohorts A and B for MDD, except for RGS20, which we followed up based upon Cohort A only. These genes selected for qPCR analyses met the criteria of FDR at the level of accepting 5\% false positives and percentage change greater than $20 \%$ in the ACC microarray results. The threshold cycle $\left(\mathrm{C}_{t}\right)$ values for the target transcripts were normalized to averaged $\mathrm{C}_{t}$ values for two reference transcripts, Jagged 1 (JAG1) and solute carrier family 9 isoform 1 (SLC9A1), which showed equivalent expression levels among the three diagnostic groups (BPD, MDD, and control) throughout the 3 brain regions on our normalized microarray data. After DNase digestion and purification, total RNA $(1 \mu \mathrm{g})$ samples from each of the 34 subjects in Cohorts A and B were used as a template for first-strand cDNA synthesis using poly-dT primer. The mRNA for each transcript was measured using the SybrGreen system with Prism model 7000-sequence detection instrument (Applied Biosystems, Foster City, California) and primer sequences listed in Table S1. The $\mathrm{C}_{t}$, which correlatedinversely with the target mRNA concentration, was measured as the cycle number at which the SybrGreen fluorescent signal increased abovea pre-set threshold level. The qPCR experiments were performed three times for each transcript, and the $C_{t}$ triplicate values were averaged.

\section{In situ HYBRIDIZATION}

The gene expression fold changes for GPRC5B and GPR37 showed an increase in BPD and decrease in MDD. We selected those genes for in situ hybridization (ISH) using the ACC regions from six representative subjects to evaluate the cellular localization of GPRC5B and GPR37 mRNA expression. A formal statistical analysis of the ISH data was not applied due to low subject number. ISH was performed following a protocol as described elsewhere (Neal et al., 2001; Lopez-Figueroa et al., 2004). Briefly, frozen ACC tissue blocks were cut into $12-\mu \mathrm{m}$ sections on a cryostat. After fixation with $4 \%$ paraformaldehyde for $1 \mathrm{~h}$, sections were hybridized overnight with a ${ }^{35}$ S-labeled antisense cRNA probes for GPRC5B and GPR37. Following hybridization, wash, RNase A treatment, dehydration and air-dry, sections were exposed to Kodak XAR-5 X-ray film for 21 days. Technical control studies were performed by (1) using ${ }^{35}$ S-labeled sense RNA probes for GPRC5B and GPR37, and (2) pre-treating tissue with RNase A before hybridizing with the antisense probes.

\section{RESULTS}

Significantly dysregulated GPLS genes that passed FDR $(p<$ $0.05)$ in either Cohort A or B and either mood disorder, BPD 
or MDD, are listed in Table 2. For completeness, the uncorrected p-values are also shown, as some genes only met FDR for a single comparison. In general, equal numbers of GPLS genes passed FDR in BPD and MDD in the ACC (10 genes for BPD and 10 genes for MDD that passed FDR), compared with DLPFC (1 gene for BPD and 5 genes for MDD). Thus, about three fold more gene expression differences in mood disorder were found in the ACC showed compared to the DLPFC. The genes in Table 2 also showed non-significant correlations between gene expression and tissue $\mathrm{pH}$ (all $p$-values $>0.1$ ) suggesting that residual $\mathrm{pH}$-agonal effects on the expression levels of GPCR genes did not remain in the data set, even though complete elimination of these factors may not be possible with matching of subject's age and $\mathrm{pH}$, and inclusion of subjects that had rapid deaths.

\section{CYCLIC AMP SIGNALING PATHWAY}

The genes involved in cAMP signaling pathways, which were differentially expressed in ACC of BPD patients compared to controls, are listed in Table 2. The cAMP signaling pathway is shown in Figure 1A. The data show that six significant transcripts out of 39 that repress cAMP signaling activity (Table 1) were increased in ACC from BPD patients at the transcriptional level. The group of molecules that act negatively on cAMP signaling activity was significantly over-represented in BPD based on a hypergeometric distribution $(p=0.037, q=0.36)$. Thus, there was a nominal enrichment of genes that act negatively on cAMP signaling activity $\left(\mathrm{G}_{i}\right.$ proteins, phosphodiesterase, protein kinase $\mathrm{A}$ inhibitors, and protein phosphatase) in BPD in the ACC.

Table 2 | GPLS genes significantly dysregulated in anterior cingulate cortex by microarray.

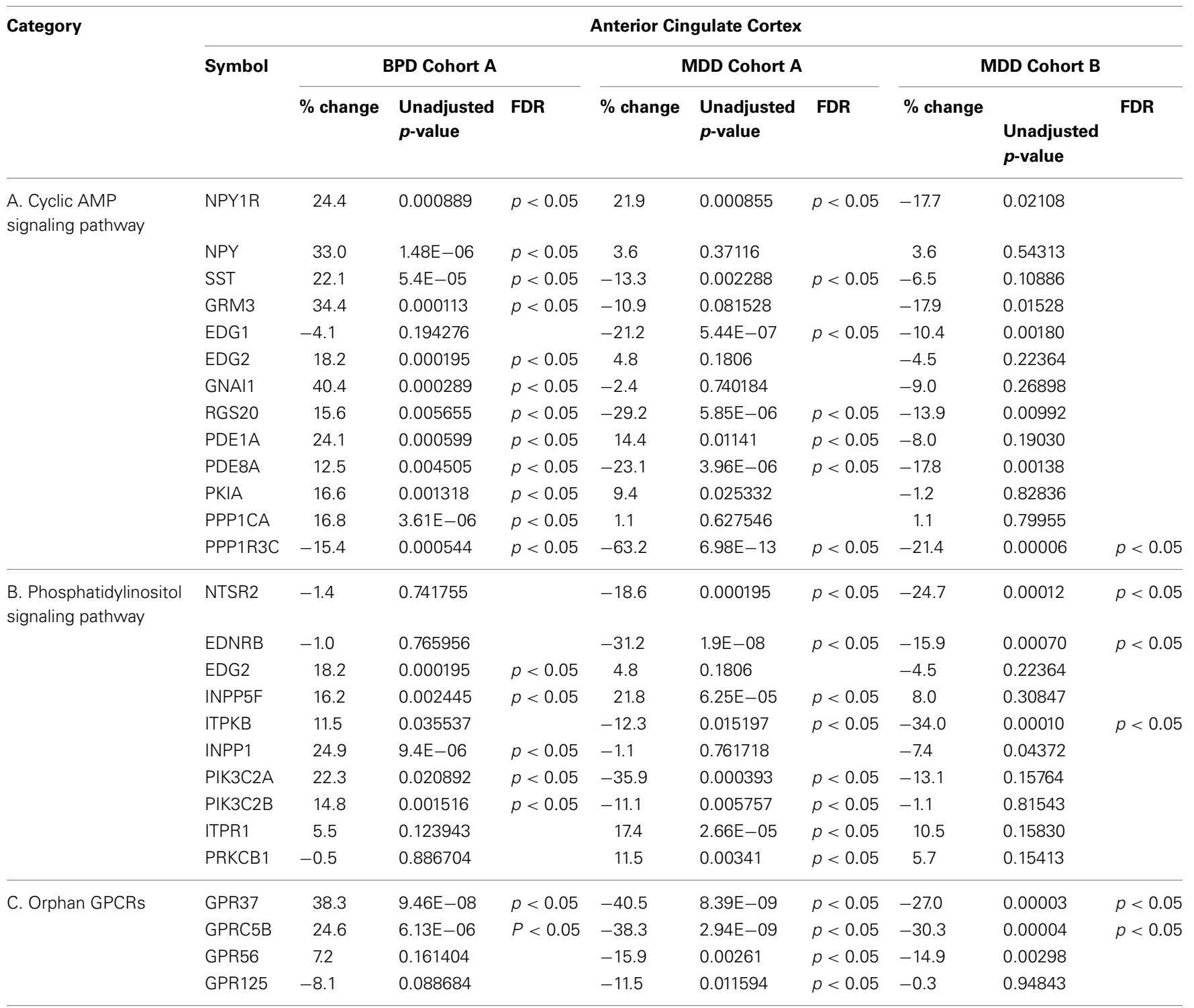

The GPLS expression percent change differences (\% change) by cohort for genes that met FDR in Cohort A or B. Blank FDR cells indicated those genes did not pass FDR. 

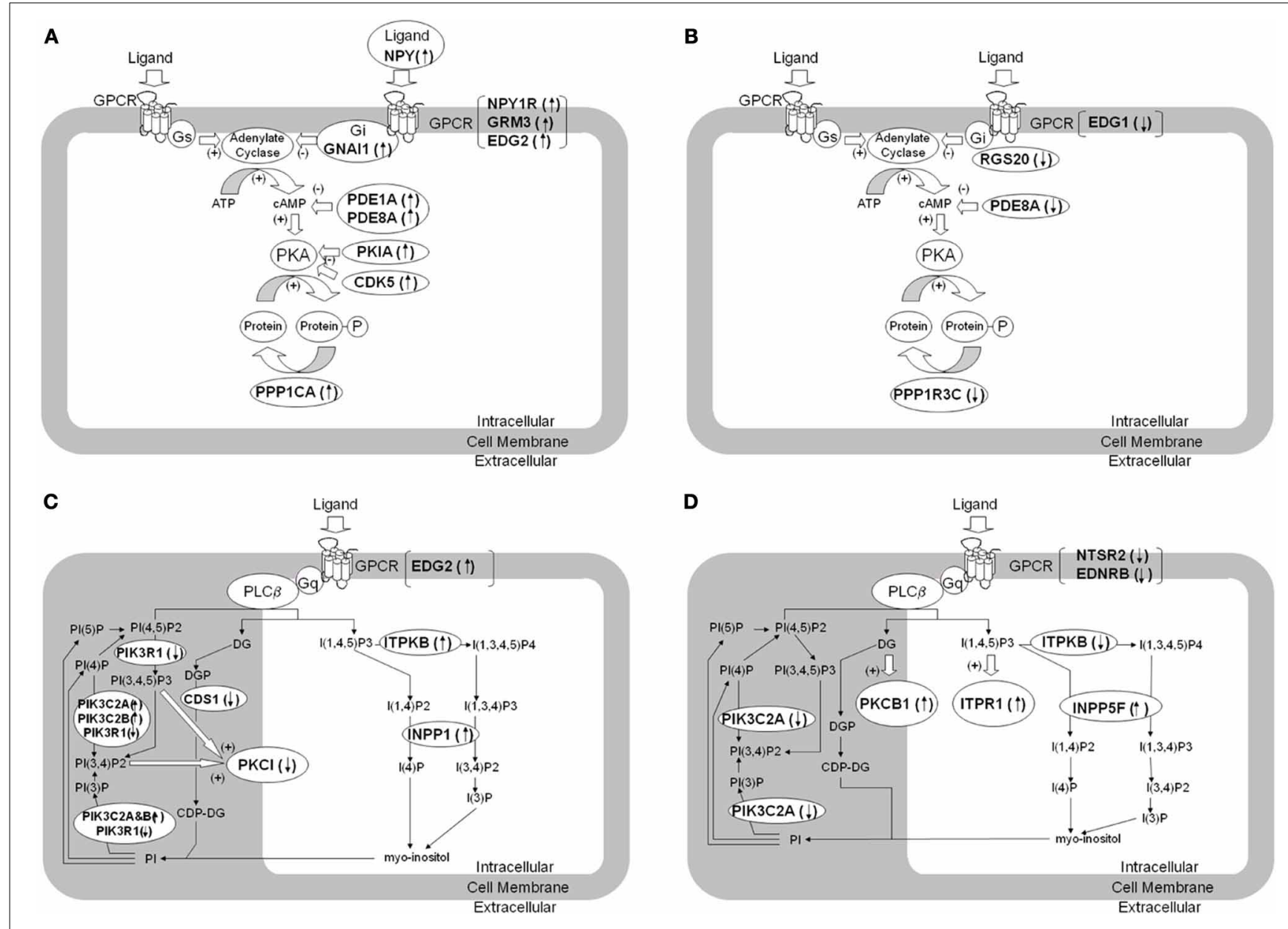

FIGURE 1 | Dysregulation of genes involved in cAMP- and phosphatidylinositol signaling pathways in brain tissue from patients with BPD and MDD. The figure summarizes differentially expressed genes regulating signaling pathways using second messengers of $\operatorname{CAMP}(\mathbf{A}, \mathbf{B})$ and phosphatidylinositol $\mathbf{( C , D )}$ in brain tissue from BPD $(\mathbf{A}, \mathbf{C})$ and MDD $(\mathbf{B}, \mathbf{D})$ compared to control subjects. The differentially expressed genes are denoted in italic and bold. (A) shows increased expression of transcripts related to suppression of CAMP mediated signaling in BPD. (B) shows decreased expression of transcripts related to suppression of CAMP mediated signaling in MDD. (C) shows altered expression of transcripts related to phosphatidylinositol mediated signaling in BPD. (D) shows altered expression of transcripts related to phosphatidylinositol mediated signaling in MDD. GNAI1, G protein alpha inhibiting activity 1; RGS20, Regulator of G-protein

signaling 20; PDE1A, Phosphodiesterase 1A; PDE8A, Phosphodiesterase 8A; PKIA, Protein kinase A inhibitor alpha; PPP1CA, Protein phosphatase 1, catalytic alpha; PPP1R3C, Protein phosphatase 1, regulatory 3C; INPP5F, Inositol polyphosphate-5-phosphatase F; ITPKB, Inositol 1,4,5-trisphosphate 3-kinase B; INPP1, Inositol polyphosphate-1-phosphatase; CDS1,

CDP-diacylglycerol synthase 1; PIK3C2A, Phosphoinositide-3-kinase catalytic 2A; PIK3C2B, Phosphoinositide-3-kinase catalytic 2B; PIK3R1,

Phosphoinositide-3-kinase regulatory 1 ; PRKCl, Protein kinase $\mathrm{C}$ iota; ITPR1, Inositol 1,4,5-triphosphate receptor 1; PRKCB1, Protein kinase $C$ beta 1; NPY, Neuropeptide $Y$; NPY1R, Neuropeptide $Y$ receptor $Y 1$; NTSR2, Neurotensin receptor 2; EDNRB, Endothelin receptor type B; GRM3, Metabotropic Glutamate receptor 3; EDG1, Endothelial differentiation GPCR 1; EDG2, Endothelial differentiation GPCR 2.

In contrast, of those genes that repressed cAMP signaling activity in MDD (Figure 1B and Table 2) there was only one gene (PDE8A) differentially expressed, hence this signaling pathway was not over-represented $(p>0.05)$.

\section{$\mathbf{G}_{\boldsymbol{s}} / \mathbf{G}_{\boldsymbol{i}}$-coupled GPCRs}

Significant increases of NPY and NPY1R mRNA expression were found in BPD in ACC. GRM3 expression was also increased in ACC of BPD patients. $\mathrm{G}_{i} / \mathrm{G}_{12}$-linked EDG2 was increased in ACC of BPD, while $\mathrm{G}_{i}$-linked EDG1 was decreased in ACC of MDD. EDG1 and EDG2 regulate neuronal and glial functions, including neurite retraction, neurogenesis, and axonal guidance (Takuwa et al., 2002).

\section{G proteins}

Our data showed an increase of GNAI1 in the ACC of BPD, but no change in GNAI1 expression in the DLPFC of BPD. Consistent with our findings in DLPFC, immunoreactivity and functional activity of $\mathrm{G}_{\mathrm{i}}$ protein is not altered in the frontal cortex of BPD (Young et al., 1993; Friedman and Wang, 1996). RGS20 was significantly decreased in ACC of MDD cases.

\section{Adenylate cyclase and protein kinase $A$}

Expression levels of transcripts coding adenylate cyclases and cAMP-dependent protein kinases (PKAs) were not altered in BPD and MDD compared with controls in our study, which is consistent with a previous study (Chang et al., 2003). The reported 
dysregulation in functional activities of adenylate cyclase and PKA (Gould and Manji, 2002) may not be due to alterations at the transcript level in the brain cortices.

\section{Phosphatidylinositol signaling pathway}

The phosphatidylinositol (PI) signaling pathway related genes which were differentially expressed in ACC of BPD patients are shown in Figure 1C and are summarized Table 2. The group of phosphatidylinositol 3-kinases was significantly over-represented in BPD based on a hypergeometric distribution $(p=0.042$; $q=0.36)$.

The PI signaling pathway related genes which were differentially expressed in ACC of MDD patients compared with controls are summarized in Figure 1D and Table 2. Since antidepressants have been reported to affect PI signaling (Dwivedi et al., 2002; Quintero et al., 2005), the potential effect of drug treatment on the gene expression was considered. In cohort A, five MDD subjects were prescribed SSRI at the time of death, whereas remaining four MDD subjects were not prescribed and presumably not taking any SSRIs (Table 1). There were no significant differences in mRNA expressions of PKCB1, ITPR1 and INPP5F between SSRItreated MDD and non-SSRI-treated MDD groups. However, ITPKB mRNA expression was significantly lower in the nonSSRI-treated MDD group than the SSRI-treated MDD group, which suggests that SSRIs may attenuate the altered expression in MDD toward levels observed in controls.

\section{$\mathbf{G}_{\boldsymbol{q}}$-coupled GPCRs}

NTSR2 was decreased in ACC of BPD. NTSR2 mRNA and NTSR2 binding was reported to be down regulated in transgenic mice over expressing corticotrophin releasing factor, which is linked to anxiety, stress and depression (Peeters et al., 2004). EDNRB was also decreased in ACC of MDD. Endothelin is known to be a vasoconstrictor peptide as well as a neuromodulator regulating neuronal excitability. The data did not show any significant differences in expression levels of $\mathrm{G}_{q}$-linked monoamine GPCRs (serotonin-2 receptors and adrenergic alpha-1 receptors), which was consistent with previous microarray studies (Iwamoto et al., 2004; Konradi et al., 2004; Sibille et al., 2004; Aston et al., 2005).

\section{Lithium and second messengers}

The microarray data highlighted several target molecules of lithium treatment (Figure 1C). Lithium is known to block INPP1 (inositol polyphosphate-1-phosphatase) enzyme activity, and INPP1 mRNA expression was increased in ACC of BPD. Among the 6 BPD subjects, 3 BPD subjects treated with lithium at the time of death showed lower signal intensities for INPP1 and PIK3C2B compared with remaining nonlithium treated BPD subjects, although the difference did not reach significant changes. There is a modest genetic association between INPP1 and sensitivity to lithium treatment (Steen et al., 1998; Serretti, 2002). A second activity of lithium is activation of phosphatidylinositol 3-kinases and regulation of glycogen synthesis kinase 3 beta (GSK3B) activity (Sinha et al., 2005).

For MDD subjects, the mRNA expression of PKCB1, ITPR1, and INPP5F were increased in ACC, while ITPKB mRNA was decreased (Figure 1D). PKCB1 and ITPR1 are receptors for diacylglycerol (DG) and inositol 1, 4, 5-triphosphate (ITP), respectively, both of which are intracellular second messengers produced by PLC-beta through a $G_{q}$ protein-dependent mechanism, while INPP5F and ITPKB metabolize ITP in a signal-terminating reaction. Previous reports suggest decreased PLC-beta activity in depressed patients (Pandey et al., 1997; Frey et al., 1998; Moore et al., 1999), and over expressed PKCB1 may down regulate PLC-beta activity (Pachter et al., 1992). The alterations in expression levels of the molecules interacting with DG and ITP may reflect functional impairments of $\mathrm{G}_{q}$ and PLC-beta in MDD.

\section{ORPHAN G PROTEIN-COUPLED RECEPTORS}

The two GPCRs that showed the most consistent differential expression patterns through both mood disorder analyses were GPCR family C, group 5, member B (GPRC5B) and G proteincoupled receptor 37 (GPR37)as shown in Table 2 and validated by QPCR (Table 3). GPRC5B was significantly increased in ACC of BPD patients and in DLPFC of BPD. GPR37 was also significantly increased in ACC of BPD. GPRC5B was significantly decreased in ACC and DLPFC of MDD patients.

\section{REAL TIME QUANTITATIVE PCR}

We followed up on results primarily that met FDR in cohort A for BPD, and both Cohorts A and B for MDD, except for RGS20, which we followed up based upon Cohort A meeting FDR while Cohort B met uncorrected p-value significance only. Nine GPLS transcripts were selected for validation, five for BPD and four for MDD. The qPCR results showed 100\% concordance between $\mathrm{qPCR}$ and microarray fold change for BPD in ACC (Table 3) and 4/5 transcripts were statistically significant. Four GPLS related transcripts showed 100\% concordance between qPCR and microarray fold change for MDD in ACC (Table 3 ) and 4/4 transcripts were statistically significant. NPY, GPRC5B, GPR37, and INPP1 were significantly increased in ACC of BPD, whereas GPRC5B, GPR37, RGS20, and PPP1R3C were significantly decreased in the ACC of MDD.

\section{In situ HYBRIDIZATION HISTOCHEMISTRY}

GPR37 mRNA was preferentially expressed in subcortical white matter. The sense probe hybridization signal showed background signal. GPR37 mRNA expression in subcortical white matter was higher in ACC of both of the BPD subjects compared to both of the control subjects, whereas GPR37 mRNA expression in subcortical white matter was lower in ACC of both of the MDD subjects compared to both of the control subjects (Figure 2). This preliminary data suggests that the significant differential microarray and QPCR expressions of GPR37 between BPD/MDD and controls may reflect altered expression levels of GPR37 mRNA in subcortical white matter. mRNA expression of GPRC5B was not specific in ACC samples tested, most likely due to strong background hybridization issues.

\section{DISCUSSION}

The results of the study of GPLS transcriptional profiling showed differences in BPD and MDD in both the CAMP- and 
Table 3 | Quantitative PCR data summary of anterior cingulate cortex (ACC) genes in BPD or MDD that showed altered expression compared to the control group.

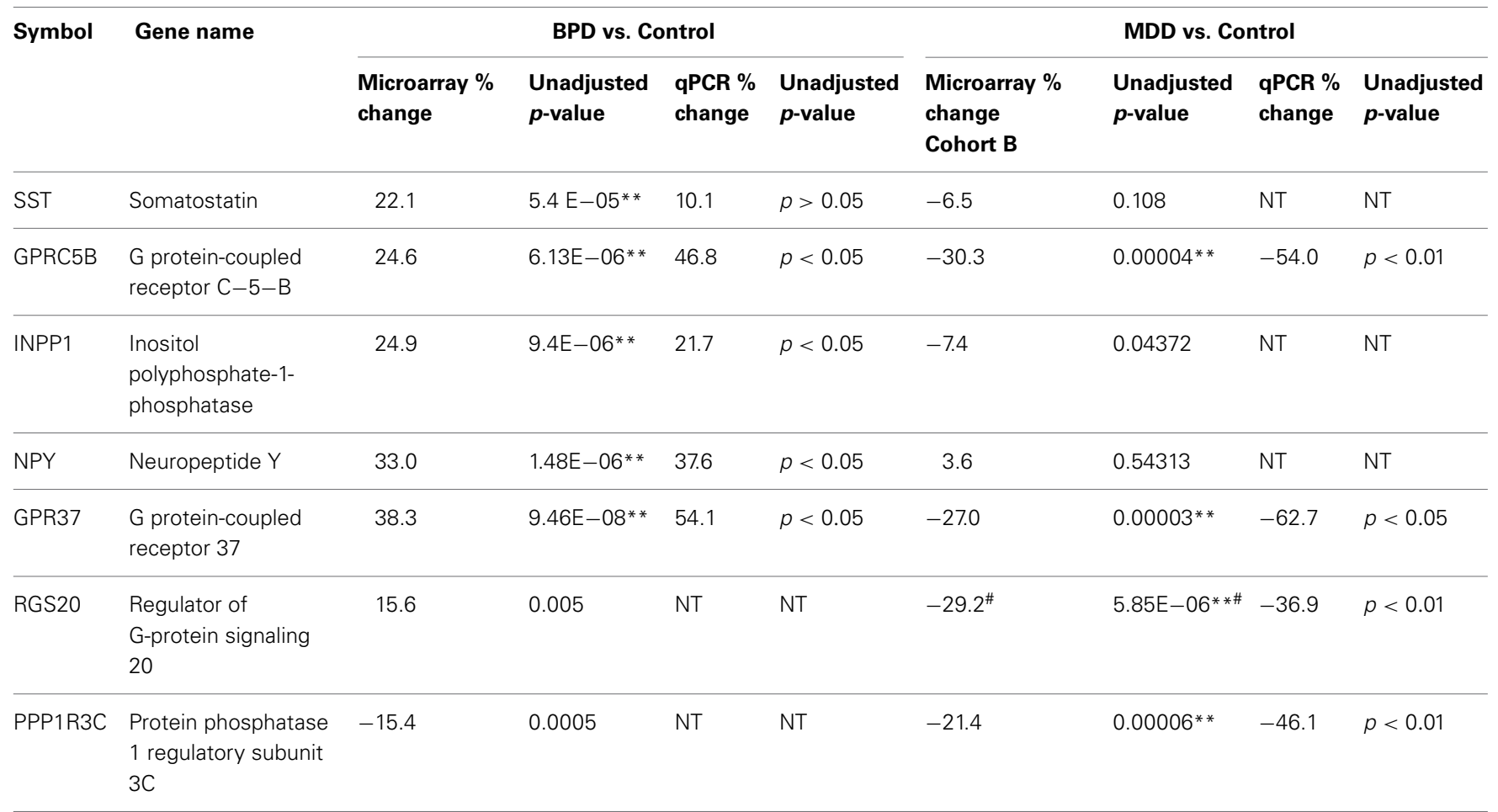

These genes selected for qPCR analyses met the criteria of false discovery rate multiple testing correction at the level of accepting $5 \%$ false positives and percentage change greater than $20 \%$ in the anterior cingulate cortex microarray results in Cohort A for BPD, and in Cohort B for MDD. The qPCR analyses were run for seven representative GPLS selected from ligand peptides, GPCRs, and G protein regulators.

NT, not tested by qPCR as did not meet criteria of $20 \%$ change and passing FDR by microarray.

${ }^{*}$ Indicates a gene that passed FDR.

${ }^{\#} R G S 20$ values shown are for Cohort $A$.

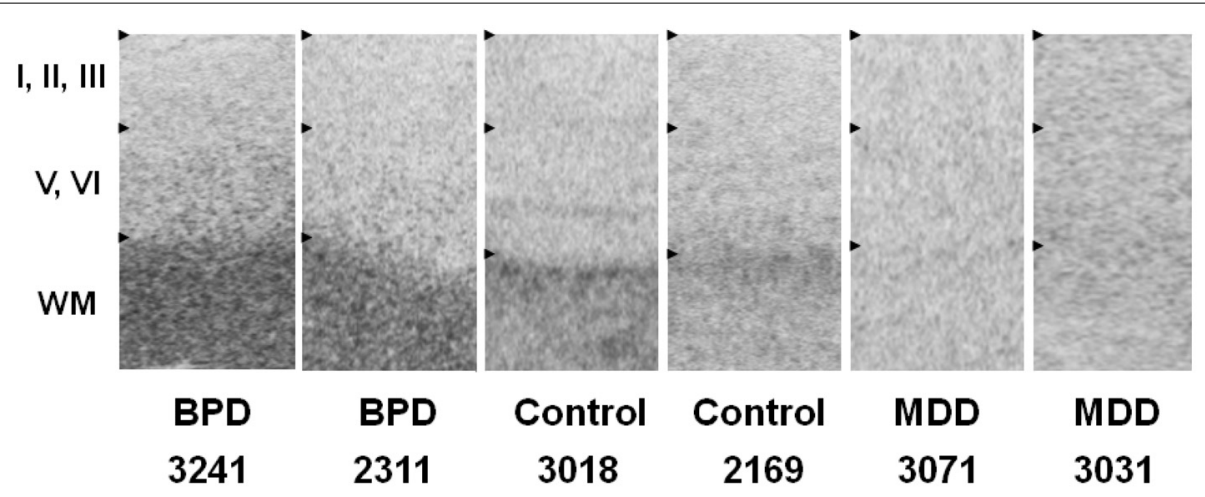

FIGURE 2 | In situ hybridization images of GPR37 mRNA in representative BPD, MDD and control subjects. GPR37 mRNA is preferentially expressed in subcortical white matter. Among six layers of cortical gray matter, GPR37 expression in deeper layers $(\mathrm{V}-\mathrm{VI})$ is relatively higher than in superficial layer
(I-III). Expression levels in GPR37 is increased in the BPD subjects, and decreased in MDD subjects in subcortical white matter in anterior cingulate cortex tissue, compared to control subjects. WM, Subcortical white matter; BPD, Bipolar disorder; MDD, Major depressive disorder. phosphatidylinositol signaling pathways. The following pattern of alterations in GPLS were observed:

(1) Transcriptional levels of molecules acting as negative regulators in cAMP signaling pathways are increased in BPD and decreased in MDD, which may compensate for the activated cAMP signaling activity in BPD and the blunted cAMP signaling activity in MDD,

(2) Expression of PRKCB1, ITPR1, INPP5F, and ITPKB were altered in MDD, which may reflect functional impairments of $\mathrm{G}_{\mathrm{q}}$ and PLC-beta in the disorder, 
(3) Expression of INPP1 and phosphatidylinositol 3-kinases were altered in BPD suggesting that these molecules may be involved in both the pathophysiology and the mechanism(s) of action of lithium treatment of BPD, and

(4) Two orphan GPCR genes, GPRC5B and GPR37, showed significant increases in ACC of BPD, and decreases in ACC and DLPFC of MDD.

\section{ORPHAN G PROTEIN-COUPLED RECEPTORS}

Among all GPCRs, the most consistent differential expression patterns were observed for GPRC5B and GPR37. GPRC5B was significantly increased in ACC and DLPFC of BPD, while significantly decreased in ACC and DLPFC of MDD patients. GPR37 was significantly increased in ACC of BPD, and significantly decreased in ACC and DLPFC of MDD patients. The consistent cortical alterations of GPRC5B and GPR37 expression observed in MDD patients suggest a role of these genes in the pathophysiology of MDD. So far, these two orphan GPCRs have not been highlighted as candidate susceptible genes for BPD and MDD, however previous microarray data supports decrease of both GPRC5B and GPR37 expressions in MDD patients (Aston et al., 2005). Our microarray data strongly suggests these genes might be involved in the pathophysiology of the disorders. GPR37 and GPRC5B are both implicated in Parkinson's disease (Marazziti et al., 2009, 2011), which has depression as one premorbid indicator, possibly concomitant with brain neurodegenerative processes.

GPR37 appears to facilitate dopamine neurotransmission, and reductions in brain GPR37 leads to behavioral alterations in conditioned place preferences to reinforcements such as cocaine or amphetamine (Marazziti et al., 2011). GPR37 (Class A receptor) contains a large extracellular domain which led to speculations that the ligand of this receptor may be a protein rather than a peptide (Leng et al., 1999). GPR37 is predominantly expressed in the brain (Zeng et al., 1997; Marazziti et al., 1998; Leng et al., 1999), especially in glial cells of the fiber tracts, Purkinje cells in cerebellum, neuronal cells in hippocampus CA3 region and substantianigra (Zeng et al., 1997; Imai et al., 2001). GPR37 has been shown to be involved in the dopaminergic system (Imai et al., 2001, 2002; Marazziti et al., 2004). GPR37 is also called Pael receptor (PAELR). Unfolded PAELR is a substrate of E3 ubiquitin ligase Parkin, and accumulation of Pael- $\mathrm{R}$ in the endoplasmic reticulum (ER) of dopaminergic neurons is considered to induce ER stress leading to neurodegeneration in Parkinson disease (Imai et al., 2002). Gpr37 ${ }^{-/-}$mice shows reduced striatal dopamine content and enhanced amphetamine sensitivity (Marazziti et al., 2004). Our ISH data suggest that the predominant expression of GPR37 mRNA in ACC occurred mainly in subcortical white matter. GPR37 is a substrate of parkin (PARK2), and its insoluble aggregates accumulate in brain tissue samples of Parkinson's disease patients, AKA PaelR (Marazziti et al., 2009).

GPRC5B is phylogenetically classified into a type C GPCR, however, in contrast to other type $\mathrm{C}$ genes, GPRC5B has a short $\mathrm{N}$ terminal domain (Brauner-Osborne and Krogsgaard-Larsen, 2000). QPCR based expression analysis shows GPRC5B is predominantly expressed in brain, with most abundant expression in neuronal cells of caudate, putamen, substantia nigra, thalamus and hippocampus and glial cells of the fiber tracts (BraunerOsborne and Krogsgaard-Larsen, 2000; Robbins et al., 2002). Behavioral abnormalities exist in GPRC5B knock-outs, decreased spontaneous locomotor activity, and decreased responses to a new environment (Sano et al., 2011).

The expression patterns of GPRC5B and GPR37 suggest that both of these orphan GPCRs may be involved in various cellular functional activities in the brain including neuronal and glial cells. Functional characterization of GPRC5B and GPR37 may provide new insights into the pathophysiology of mood disorder, and potential novel strategies for developing methods for diagnoses and treatment of the disorders.

There are limitations to this post-mortem study of GPLS pathway expression. We conducted seven $\mathrm{qPCR}$ validations of genes that passed FDR, and although a small number, those genes did represent large enough percent fold changes to validate by qPCR. Other technologies could be used that are less costly, such as Nanostring or Fluidigm for additional validation studies, which are now being conducted on larger sample sizes. In addition, we do not have confirmed toxicological analysis of all drugs of abuse and therapeutic levels to rule out these effects in explaining case-control expression differences. Finally, we are aware that small residual agonal effects might exist that are not corrected in this analysis, however we did confirm that the present data presented in Table 2, was not due to the effects of age or $\mathrm{pH}$ on gene expression.

\section{SUMMARY}

This study highlights transcript profile differences in GPLS pathways in both BPD and MDD. Since sample sizes were low, we also used a second independent cohort in the case of MDD gene expression to check concordance. We relied upon duplicate microarray analysis at independent laboratories, and used gene expression values that were significantly correlated between sites, and employed FDR to select genes to advance for qPCR experimental validations.

The disturbances observed in cAMP- and phosphatidylinositol- pathway regulation may be due to differential activation of individual GPCRs and individual differences in ligand- receptor sensitivity, suggesting that functional and genetic characterization of these candidate genes may provide further understanding of the pathophysiology of mood disorders. Further studies will also be required to investigate additional GPCR signaling pathway features such as receptor phosphorylation, beta-arrestin recruitment, receptor desensitization, and internalization, and beta-gamma mediated signaling. The results of the present study suggest that future functional activity studies of the GPLS pathways would elucidate the relationship of the observed transcript changes to protein levels and functional outcomes in mood disorders.

\section{ACKNOWLEDGMENTS}

Authors of this manuscript were members of the Silvio O. Conte Center for "Genomic Studies in Bipolar and Major Depression" which was supported by the NIMH grant P50 MH60398, and the Pritzker Neuropsychiatric Disorders Research Consortium currently supported by the Pritzker Neuropsychiatric Disorders 
Research Fund L.L.C. A shared intellectual property agreement exists between the Fund and all the universities involved, in order to encourage the development of appropriate findings for research and clinical applications. The academic and philanthropic entities involved in this research program are jointly filing patent applications related to the present findings. This project is also supported by Della Martin Foundation (UCI), William Lion Penzner Foundation (UCI), and the NIMH MH42251 (Stanley J. Watson and Huda Akil), and MH085801 (Marquis P. Vawter) and MH099440 (Marquis P. Vawter). We appreciate the assistance of Preston Cartagena, Psy.D., David Walsh, Ph.D., and Richard Stein, Ph.D. of the University of California, Irvine (UCI) Brain Repository for their contributions to post-mortem clinical characterization of subjects, and Kathleen Burke (UCI), Claudia M. Cervantes (UCI) for procurement of brain tissue, as well as Chief Deputy Coroner Jacque Berndt, and the staff of Orange County Coroners' Office. Neuropathological evaluation of the post-mortem brains was performed by F. Warren Lovell, M.D. Tissue specimens were processed and stored at the Human Brain and Spinal Fluid Resource Center, Veteran's Medical Center, Los Angeles under the direction of Wallace W. Tourtellotte, M.D., Ph.D. We also appreciate the technical contributions of Ling Shao, Kevin M. Overman, Sharon M. Burke (U Mich), as well as critical reviews by Hans-Peter Nothacker (UCI, Department of Pharmacology) and Blynn Bunney (UCI).

\section{SUPPLEMENTARY MATERIAL}

The Supplementary Material for this article can be found online at: http://www.frontiersin.org/journal/10.3389/fgene. 2013.00297/abstract.

\section{REFERENCES}

Agam, G., Shaltiel, G., Kozlovsky, N., Shimon, H., Belmaker, R. H., and Shatiel, G. (2003). Lithium inhibitable enzymes in postmortem brain of bipolar patients. J. Psychiatr. Res. 37, 433-442. doi: 10.1016/S0022-3956(03)00044-X

Aston, C., Jiang, L., and Sokolov, B. P. (2005). Transcriptional profiling reveals evidence for signaling and oligodendroglial abnormalities in the temporal cortex from patients with major depressive disorder. Mol. Psychiatry. 10, 309-322. doi: 10.1038/sj.mp.4001565

Atz, M., Walsh, D., Cartagena, P., Li, J., Evans, S., Choudary, P., et al. (2007). Methodological considerations for gene expression profiling of human brain. J. Neurosci. Methods 163, 295-309. doi: 10.1016/j.jneumeth. 2007.03.022

Brauner-Osborne, H., and Krogsgaard-Larsen, P. (2000). Sequence and expression pattern of a novel human orphan G-protein-coupled receptor, GPRC5B, a family $\mathrm{C}$ receptor with a short amino-terminal domain. Genomics 65, 121-128. doi: 10.1006/geno.2000.6164

Caberlotto, L., and Hurd, Y. L. (2001). Neuropeptide Y Y(1) and Y(2) receptor mRNA expression in the prefrontal cortex of psychiatric subjects. Relationship of Y(2) subtype to suicidal behavior. Neuropsychopharmacology 25, 91-97. doi: 10.1016/S0893-133X(00)00231-1

Carvajal, C., Dumont, Y., and Quirion, R. (2006). Neuropeptide y: role in emotion and alcohol dependence. CNS Neurol. Disord. Drug Targets 5, 181-195. doi: $10.2174 / 187152706776359592$

Chang, A., Li, P. P., and Warsh, J. J. (2003). cAMP-Dependent protein kinase (PKA) subunit mRNA levels in postmortem brain from patients with bipolar affective disorder (BD). Brain Res. Mol. Brain Res. 116, 27-37. doi: 10.1016/S0169328X(03)00211-0

Choudary, P. V., Molnar, M., Evans, S. J., Tomita, H., Li, J. Z., Vawter, M. P., et al. (2005). Altered cortical glutamatergic and GABAergic signal transmission with glial involvement in depression. Proc. Natl. Acad. Sci. U.S.A. 102, 15653-15658. doi: $10.1073 /$ pnas.0507901102
Dai, M., Wang, P., Boyd, A. D., Kostov, G., Athey, B., Jones, E. G., et al. (2005). Evolving gene/transcript definitions significantly alter the interpretation of GeneChip data. Nucleic Acids Res. 33, e175. doi: 10.1093/nar/gnil79

Donati, R. J., and Rasenick, M. M. (2003). G protein signaling and the molecular basis of antidepressant action. Life Sci. 73, 1-17. doi: 10.1016/S00243205(03)00249-2

Dwivedi, Y., Agrawal, A. K., Rizavi, H. S., and Pandey, G. N. (2002). Antidepressants reduce phosphoinositide-specific phospholipase $C$ (PI-PLC) activity and the mRNA and protein expression of selective PLC beta 1 isozyme in rat brain. Neuropharmacology 43, 1269-1279. doi: 10.1016/S0028-3908(02)00253-8

Dwivedi, Y., Mondal, A. C., Shukla, P. K., Rizavi, H. S., and Lyons, J. (2004). Altered protein kinase a in brain of learned helpless rats: effects of acute and repeated stress. Biol. Psychiatry 56, 30-40. doi: 10.1016/j.biopsych.2004.03.018

Elhwuegi, A. S. (2004). Central monoamines and their role in major depression. Prog. Neuropsychopharmacol. Biol. Psychiatry 28, 435-451. doi: 10.1016/j.pnpbp.2003.11.018

Escriba, P. V., Ozaita, A., and Garcia-Sevilla, J. A. (2004). Increased mRNA expression of alpha2A-adrenoceptors, serotonin receptors and mu-opioid receptors in the brains of suicide victims. Neuropsychopharmacology 29, 1512-1521. doi: 10.1038/sj.npp.1300459

Evans, S. J., Choudary, P. V., Neal, C. R., Li, J. Z., Vawter, M. P., Tomita, H., et al. (2004). Dysregulation of the fibroblast growth factor system in major depression. Proc. Natl. Acad. Sci. U.S.A. 101, 15506-15511. doi: 10.1073/pnas.0406788101

Frazier, J. A., Ahn, M. S., DeJong, S., Bent, E. K., Breeze, J. L., and Giuliano, A. J. (2005). Magnetic resonance imaging studies in early-onset bipolar disorder: a critical review. Harv. Rev. Psychiatry 13, 125-140. doi: 10.1080/10673220591003597

Frey, R., Metzler, D., Fischer, P., Heiden, A., Scharfetter, J., Moser, E., et al. (1998). Myo-inositol in depressive and healthy subjects determined by frontal $1 \mathrm{H}$ magnetic resonance spectroscopy at 1.5 tesla. J. Psychiatr. Res. 32, 411-420. doi: 10.1016/S0022-3956(98)00033-8

Friedman, E., and Wang, H. Y. (1996). Receptor-mediated activation of G proteins is increased in postmortem brains of bipolar affective disorder subjects. J. Neurochem. 67, 1145-1152. doi: 10.1046/j.1471-4159.1996.67031145.x

Gould, T. D., and Manji, H. K. (2002). Signaling networks in the pathophysiology and treatment of mood disorders. J. Psychosom. Res. 53, 687-697. doi: 10.1016/S0022-3999(02)00426-9

Gurevich, I., Tamir, H., Arango, V., Dwork, A. J., Mann, J. J., and Schmauss, C. (2002). Altered editing of serotonin 2C receptor pre-mRNA in the prefrontal cortex of depressed suicide victims. Neuron 34, 349-356. doi: 10.1016/S08966273(02)00660-8

Harrison, P. J. (2002). The neuropathology of primary mood disorder. Brain 125(Pt 7), 1428-1449. doi: 10.1093/brain/awf149

Harwood, A. J. (2005). Lithium and bipolar mood disorder: the inositol-depletion hypothesis revisited. Mol. Psychiatry 10, 117-126. doi: 10.1038/sj.mp.4001618

Imai, Y., Soda, M., Hatakeyama, S., Akagi, T., Hashikawa, T., Nakayama, K. I., et al. (2002). CHIP is associated with Parkin, a gene responsible for familial Parkinson's disease, and enhances its ubiquitin ligase activity. Mol. Cell 10, 55-67. doi: 10.1016/S1097-2765(02)00583-X

Imai, Y., Soda, M., Inoue, H., Hattori, N., Mizuno, Y., and Takahashi, R. (2001). An unfolded putative transmembrane polypeptide, which can lead to endoplasmic reticulum stress, is a substrate of Parkin. Cell 105, 891-902. doi: 10.1016/S00928674(01)00407-X

Iwamoto, K., Kakiuchi, C., Bundo, M., Ikeda, K., and Kato, T. (2004). Molecular characterization of bipolar disorder by comparing gene expression profiles of postmortem brains of major mental disorders. Mol. Psychiatry. 9, 406-416. doi: 10.1038/sj.mp.4001437

Jope, R. S., Song, L., Li, P. P., Young, L. T., Kish, S. J., Pacheco, M. A., et al. (1996). The phosphoinositide signal transduction system is impaired in bipolar affective disorder brain. J. Neurochem. 66, 2402-2409.

Karege, F., Bovier, P., Rudolph, W., and Gaillard, J. M. (1996). Platelet phosphoinositide signaling system: an overstimulated pathway in depression. Biol. Psychiatry 39, 697-702. doi: 10.1016/0006-3223(95)00187-5

Kim, S., and Webster, M. J. (2010). Correlation analysis between genome-wide expression profiles and cytoarchitectural abnormalities in the prefrontal cortex of psychiatric disorders. Mol. Psychiatry 15, 326-336. doi: 10.1038/mp.2008.99

Konradi, C., Eaton, M., MacDonald, M. L., Walsh, J., Benes, F. M., and Heckers, S. (2004). Molecular evidence for mitochondrial dysfunction in 
bipolar disorder. Arch. Gen. Psychiatry 61, 300-308. doi: 10.1001/archpsyc.61. 3.300

Kuromitsu, J., Yokoi, A., Kawai, T., Nagasu, T., Aizawa, T., Haga, S., et al. (2001). Reduced neuropeptide Y mRNA levels in the frontal cortex of people with schizophrenia and bipolar disorder. Gene Expr. Patterns 1, 17-21. doi: 10.1016/S1567-133X(01)00003-5

Leng, N., Gu, G., Simerly, R. B., and Spindel, E. R. (1999). Molecular cloning and characterization of two putative $G$ protein-coupled receptors which are highly expressed in the central nervous system. Brain Res. Mol. Brain Res. 69, 73-83. doi: 10.1016/S0169-328X(99)00092-3

Li, J. Z., Vawter, M. P., Walsh, D. M., Tomita, H., Evans, S. J., Choudary, P. V., et al. (2004). Systematic changes in gene expression in postmortem human brains associated with tissue $\mathrm{pH}$ and terminal medical conditions. Hum. Mol. Genet. 13, 609-616. doi: 10.1093/hmg/ddh065

Lieb, K., Treffurth, Y., Berger, M., and Fiebich, B. L. (2002). Substance P and affective disorders: new treatment opportunities by neurokinin 1 receptor antagonists? Neuropsychobiology 45(Suppl. 1), 2-6. doi: 10.1159/000049254

Lopez-Figueroa, A. L., Norton, C. S., Lopez-Figueroa, M. O., ArmelliniDodel, D., Burke, S., Akil, H., et al. (2004). Serotonin 5-HT1A, 5-HT1B, and 5-HT2A receptor mRNA expression in subjects with major depression, bipolar disorder, and schizophrenia. Biol. Psychiatry 55, 225-233. doi: 10.1016/j.biopsych.2003.09.017

Marazziti, D., Di Pietro, C., Golini, E., Mandillo, S., Matteoni, R., and TocchiniValentini, G. P. (2009). Macroautophagy of the GPR37 orphan receptor and Parkinson disease-associated neurodegeneration. Autophagy 5, 741-742. doi: 10.4161/auto.5.5.8700

Marazziti, D., Di Pietro, C., Mandillo, S., Golini, E., Matteoni, R., and TocchiniValentini, G. P. (2011). Absence of the GPR37/PAEL receptor impairs striatal Akt and ERK2 phosphorylation, DeltaFosB expression, and conditioned place preference to amphetamine and cocaine. FASEB J. 25, 2071-2081. doi: 10.1096/fj.10-175737

Marazziti, D., Gallo, A., Golini, E., Matteoni, R., and Tocchini-Valentini, G. P. (1998). Molecular cloning and chromosomal localization of the mouse Gpr37 gene encoding an orphan G-protein-coupled peptide receptor expressed in brain and testis. Genomics 53, 315-324. doi: 10.1006/geno.1998.5433

Marazziti, D., Golini, E., Mandillo, S., Magrelli, A., Witke, W., Matteoni, R., et al. (2004). Altered dopamine signaling and MPTP resistance in mice lacking the Parkinson's disease-associated GPR37/parkin-associated endothelin-like receptor. Proc. Natl. Acad. Sci. U.S.A. 101, 10189-10194. doi: 10.1073/pnas.0403661101

Moore, G. J., Bebchuk, J. M., Parrish, J. K., Faulk, M. W., Arfken, C. L., StrahlBevacqua, J., et al. (1999). Temporal dissociation between lithium-induced changes in frontal lobe myo-inositol and clinical response in manic-depressive illness. Am. J. Psychiatry 156, 1902-1908.

Neal, Jr. C. R., Akil, H., and Watson, Jr. S. J. (2001). Expression of orphanin FQ and the opioid receptor-like (ORL1) receptor in the developing human and rat brain. J. Chem. Neuroanat. 22, 219-249. doi: 10.1016/S0891-0618(01)00135-1

Pachter, J. A., Pai, J. K., Mayer-Ezell, R., Petrin, J. M., Dobek, E., and Bishop, W. R. (1992). Differential regulation of phosphoinositide and phosphatidylcholine hydrolysis by protein kinase C-beta 1 overexpression. Effects on stimulation by alpha-thrombin, guanosine 5'-O-(thiotriphosphate), and calcium. J. Biol. Chem. 267, 9826-9830.

Pandey, G. N., Dwivedi, Y., Pandey, S. C., Conley, R. R., Roberts, R. C., and Tamminga, C. A. (1997). Protein kinase C in the postmortem brain of teenage suicide victims. Neurosci. Lett. 228, 111-114. doi: 10.1016/S03043940(97)00378-9

Pandey, G. N., Dwivedi, Y., Rizavi, H. S., Ren, X., Pandey, S. C., Pesold, C., et al. (2002). Higher expression of serotonin 5-HT(2A) receptors in the postmortem brains of teenage suicide victims. Am. J. Psychiatry 159, 419-429. doi: 10.1176/appi.ajp.159.3.419

Peeters, P. J., Fierens, F. L., van den Wyngaert, I., Goehlmann, H. W., Swagemakers, S. M., Kass, S. U., et al. (2004). Gene expression profiles highlight adaptive brain mechanisms in corticotropin releasing factor overexpressing mice. Brain Res. Mol. Brain Res. 129, 135-150. doi: 10.1016/j.molbrainres.2004. 06.038

Quintero, J. L., Arenas, M. I., and Garcia, D. E. (2005). The antidepressant imipramine inhibits $M$ current by activating a phosphatidylinositol 4, 5bisphosphate (PIP(2))-dependent pathway in rat sympathetic neurones. $\mathrm{Br}$. J. Pharmacol. 145, 837-843. doi: 10.1038/sj.bjp.0706239
Racagni, G., and Popoli, M. (2008). Cellular and molecular mechanisms in the long-term action of antidepressants. Dialogues Clin. Neurosci. 10, 385-400.

Robbins, M. J., Charles, K. J., Harrison, D. C., and Pangalos, M. N. (2002). Localisation of the GPRC5B receptor in the rat brain and spinal cord. Brain Res. Mol. Brain Res. 106, 136-144. doi: 10.1016/S0169-328X(02)00420-5

Rogers, M. A., Kasai, K., Koji, M., Fukuda, R., Iwanami, A., Nakagome, K., et al. (2004). Executive and prefrontal dysfunction in unipolar depression: a review of neuropsychological and imaging evidence. Neurosci. Res. 50, 1-11. doi: 10.1016/j.neures.2004.05.003

Ruhe, H. G., Mason, N. S., and Schene, A. H. (2007). Mood is indirectly related to serotonin, norepinephrine and dopamine levels in humans: a metaanalysis of monoamine depletion studies. Mol. Psychiatry 12, 331-359. doi: 10.1038/sj.mp.4001949

Sano, T., Kim, Y. J., Oshima, E., Shimizu, C., Kiyonari, H., Abe, T., et al. (2011). Comparative characterization of GPRC5B and GPRC5CLacZ knockin mice; behavioral abnormalities in GPRC5B-deficient mice. Biochem. Biophys. Res. Commun. 412, 460-465. doi: 10.1016/j.bbrc.2011.07.118

Serretti, A. (2002). Lithium long-term treatment in mood disorders: clinical and genetic predictors. Pharmacogenomics 3, 117-129. doi: 10.1517/14622416.3.1.117

Sherrin, T., Heng, K. Y., Zhu, Y. Z., Tang, Y. M., Lau, G., and Tan, C. H. (2004) Cholecystokinin-B receptor gene expression in cerebellum, pre-frontal cortex and cingulate gyrus and its association with suicide. Neurosci. Lett. 357, 107-110. doi: 10.1016/j.neulet.2003.11.072

Sibille, E., Arango, V., Galfalvy, H. C., Pavlidis, P., Erraji-Benchekroun, L., Ellis, S. P., et al. (2004).Gene expression profiling of depression and suicide in human prefrontal cortex. Neuropsychopharmacology 29, 351-361. doi: 10.1038/sj.npp.1300335

Sinha, D., Wang, Z., Ruchalski, K. L., Levine, J. S., Krishnan, S., Lieberthal, W., et al (2005). Lithium activates the Wnt and phosphatidylinositol 3-kinase Akt signaling pathways to promote cell survival in the absence of soluble survival factors. Am. J. Physiol. Renal Physiol. 288, F703-F713. doi: 10.1152/ajprenal.00189.2004

Spleiss, O., van Calker, D., Scharer, L., Adamovic, K., Berger, M., and GebickeHaerter, P. J. (1998). Abnormal G protein alpha(s) - and alpha(i2)-subunit mRNA expression in bipolar affective disorder. Mol. Psychiatry 3, 512-520. doi: 10.1038/sj.mp.4000393

Steen, V. M., Lovlie, R., Osher, Y., Belmaker, R. H., Berle, J. O., and Gulbrandsen, A. K. (1998). The polymorphic inositol polyphosphate 1-phosphatase gene as a candidate for pharmacogenetic prediction of lithium-responsive manicdepressive illness. Pharmacogenetics 8, 259-268.

Storey, J. D., and Tibshirani, R. (2003). Statistical significance for genomewide studies. Proc. Natl. Acad. Sci. U.S.A. 100, 9440-9445. doi: 10.1073/pnas. 1530509100

Takuwa, Y., Takuwa, N., and Sugimoto, N. (2002). The Edg family G protein-coupled receptors for lysophospholipids: their signaling properties and biological activities. J. Biochem. 131, 767-771. doi: 10.1093/oxfordjournals.jbchem.a003163

Tomita, H., Vawter, M. P., Walsh, D. M., Evans, S. J., Choudary, P. V., Li, J., et al. (2004). Effect of agonal and postmortem factors on gene expression profile: quality control in microarray analyses of postmortem human brain. Biol. Psychiatry 55, 348-354. doi: 10.1016/j.biopsych.2003.10.013

Vawter, M. P., Tomita, H., Meng, F., Bolstad, B., Li, J., Evans, S., et al. (2006). Mitochondrial-related gene expression changes are sensitive to agonal-pH state: implications for brain disorders. Mol. Psychiatry 11, 615, 663-679. doi: 10.1038/sj.mp.4001830

Wise, A., Jupe, S. C., and Rees, S. (2004). The identification of ligands at orphan G-protein coupled receptors. Annu. Rev. Pharmacol. Toxicol. 44, 43-66. doi: 10.1146/annurev.pharmtox.44.101802.121419

Xu, X., Muller-Taubenberger, A., Adley, K. E., Pawolleck, N., Lee, V. W., Wiedemann, C., et al. (2007). Attenuation of phospholipid signaling provides a novel mechanism for the action of valproic acid. Eukaryot Cell 6, 899-906. doi: 10.1128/EC.00104-06

Young, L. T., Asghari, V., Li, P. P., Kish, S. J., Fahnestock, M., and Warsh, J. J. (1996). Stimulatory G-protein alpha-subunit mRNA levels are not increased in autopsied cerebral cortex from patients with bipolar disorder. Brain Res. Mol. Brain Res. 42, 45-50. doi: 10.1016/S0169-328X(96)00112-X

Young, L. T., Li, P. P., Siu, K. P., Kish, S. J., and Warsh, J. J. (1993). Regional distribution of guanine nucleotide binding proteins (Gs and Gi alpha) in human brain: correlation with adenylyl cyclase activity. Neurochem. Int. 22, 285-291. doi: 10.1016/0197-0186(93)90057-C 
Zeng, Z., Su, K., Kyaw, H., and Li, Y. (1997). A novel endothelin receptor type-Blike gene enriched in the brain. Biochem. Biophys. Res. Commun. 233, 559-567. doi: 10.1006/bbrc.1997.6408

Zhou, J. N., Riemersma, R. F., Unmehopa, U. A., Hoogendijk, W. J., van Heerikhuize, J. J., Hofman, M. A., et al. (2001). Alterations in arginine vasopressin neurons in the suprachiasmatic nucleus in depression. Arch. Gen. Psychiatry 58, 655-662. doi: 10.1001/archpsyc.58.7.655

Conflict of Interest Statement: The authors declare that the research was conducted in the absence of any commercial or financial relationships that could be construed as a potential conflict of interest.

Received: 26 February 2013; accepted: 05 December 2013; published online: 23 December 2013.
Citation: Tomita H, Ziegler ME, Kim HB, Evans SJ, Choudary PV, Li JZ, Meng F, Dai M, Myers RM, Neal CR, Speed TP, Barchas JD, Schatzberg AF, Watson SJ, Akil $H$, Jones EG, Bunney WE and Vawter MP (2013) G protein-linked signaling pathways in bipolar and major depressive disorders. Front. Genet. 4:297. doi: 10.3389/ fgene.2013.00297

This article was submitted to Behavioral and Psychiatric Genetics, a section of the journal Frontiers in Genetics.

Copyright () 2013 Tomita, Ziegler, Kim, Evans, Choudary, Li, Meng, Dai, Myers, Neal, Speed, Barchas, Schatzberg, Watson, Akil, Jones, Bunney and Vawter. This is an open-access article distributed under the terms of the Creative Commons Attribution License (CC BY). The use, distribution or reproduction in other forums is permitted, provided the original author(s) or licensor are credited and that the original publication in this journal is cited, in accordance with accepted academic practice. No use, distribution or reproduction is permitted which does not comply with these terms. 